\title{
OZONE PRETREATMENT FOR THE ANAEROBIC DIGESTION OF ORGANIC SOLID WASTE
}

\author{
Alessandra Cesaro ${ }^{1,2, \star}$ and Vincenzo Belgiorno ${ }^{2}$ \\ ${ }^{1}$ Department of Civil, Architectural and Environmental Engineering, University of Napoli Federico II, via Claudio 21, 80125, Napoli, Italy \\ ${ }^{2}$ SEED - Department of Civil Engineering, University of Salerno, via Giovanni Paolo II, 84184, Fisciano (SA), Italy
}

Article Info:
Received:
14 November 2019
Revised:
14 March 2020
Accepted:
18 March 2020
Available online:
24 July 2020
Keywords:
Anaerobic digestion
Biodegradability
Energy
Methane
Municipal solid waste
Ozone

Article Info:

14 November 2019

14 March 2020

Accepted:

18 March 2020

Available online:

24 July 202

Keywords:

Biodegradability

Energy

Municipal solid waste

Ozone

\begin{abstract}
The pretreatment of organic solid waste plays a key role in achieving the highest degree of valorization within the anaerobic digestion processes. This work focuses on the use of ozone, discussing its effects, together with particle size and total solid content of waste, on the anaerobic biodegradability of the organic fraction of municipal solid waste (OFMWS). A Design of Experiment (DOE) strategy was used to identify statistically significant factors for further investigation. Experimental results showed that ozonation increased methane production, with the best results being obtained for samples characterized by the highest total solid content. The surplus methane generated by ozonated samples may also result in favourable net energy gain. These outcomes highlight the effectiveness of ozonation when applied in the pretreatment of OFMSW destined to anaerobic digestion and address the need for an energy balance to assess the competitiveness of this technology on an industrial scale.
\end{abstract}

\section{INTRODUCTION}

Anaerobic digestion is a mature technology used widely in the treatment of organic residues. The range of substrates includes high-strength wastewater, sewage sludge as well as a variety of organic solid waste (Xu et al., 2018; $\mathrm{Li}$ et al., 2019). The main aim is to generate energy from the biogas produced. Consequently, anaerobic digestion has gained a key role in contributing to the transition from a fossil fuel based economy to a bio-economy (De Vrieze et al., 2018). It can convert organic substrates, via biological routes, into a variety of value-added products, such as lactic acid, polylactic acid (PLA), succinic acid, isobutene, acrylic acid, adipic acid, ethylene and polyethylene (Dahiya et al., 2018) and energy carriers, including methane.

Nevertheless, the anaerobic digestion of solid waste still presents a number of challenges, related to the complex route to hydrolysis of organic macro-molecules into soluble compounds for microbial attack. As a result, the study of pretreatments has attracted great attention and the use of physical, chemical as well as biological processes has been assessed extensively for application to OFMSW (Ariunbaatar et al., 2014a; Cesaro and Belgiorno, 2014).

Among the chemical pretreatments options, ozonation has been investigated only at laboratory scale. The larger scale application of this technology does not appear com- petitive to other pretreatments, due to the need to operate at low ozone doses (Cesaro and Belgiorno, 2013). Successful application has been demonstrated for the treatment of sewage sludge (Sievers et al., 2004).

Ozone is a strong oxidant, which decomposes into radicals and reacts with organic substrates both directly and indirectly, via the hydroxyl ion. Cesaro and Belgiorno (2013) highlighted that ozone doses as low as $0.16 \mathrm{~g}_{03} /$ $\mathrm{g}_{\mathrm{TS}}$ can improve both the solubilisation and the anaerobic biodegradability of OFMSW. However, increasing ozone doses did not lead to higher OFMSW solubilisation effects in terms of COD: the higher ozone doses resulted in a reduction in biogas compared to untreated samples (Cesaro and Belgiorno, 2013). Ariunbaatar et al. (2014b) showed that the optimal ozone dose to enhance methane generation is highly dependent on the relative presence of sugars, lipids and proteins in the substrate. It was found that direct ozone oxidation can destroy the easily fermentable sugar, thus resulting in biomethane loss; conversely, the indirect reaction of ozone can cause the degradation of complex organic compounds such as lipids and proteins, thus enhancing biomethane generation.

These studies highlight that ozonation can be attractive as a pretreatment for organic substrates containing highly complex and difficult-to-degrade components, like OFMSW. Nevertheless, the biogas yields should take into account not only the composition of waste, but also its
* Corresponding author:

Alessandra Cesaro

email: alessandra.cesaro@unina.it
Detritus / Volume 12 - 2020 / pages 51-56 https://doi.org/10.31025/2611-4135/2020.13990 C 2019 Cisa Publisher. Open access article under CC BY-NC-ND license 
physical characteristics in terms of particle size and solids content. These can influence the effects of ozonation, promoting differential solubilization of OFMSW components.

This aspect is even more important for process scale up, since at an industrial scale organic waste is usually subjected to mechanical pretreatments, which focuses on size reduction using shredding devices. More recently, conventional shredding processes are being replaced by press-extrusion treatments that split the waste into liquid and solid fractions. The liquid fraction may account up to $85 \% \mathrm{w} / \mathrm{w}$ of the input mass of OFMSW (Novarino and Zanetti, 2012). Due to its high moisture content this can be conveniently diverted to anaerobic digestion; the solid fraction, that still contains organic material, can be sent to either composting or other recovery processes, according to its chemical-physical characteristics (Hjorth et al., 2011).

Another fundamental aspect in determining biogas yields is the solid content in the anaerobic digester. Although the production of methane is closely related to the volatile solid (VS) content of the substrate for anaerobic digestion, the total solids (TS) also affect process yields. Abbassi-Guendouz et al. (2012) evaluated the role of the TS content on anaerobic digestion. They showed that the total methane production slightly decreased as TS concentrations increased from $10 \%$ to $25 \%$, with further increase of TS up to $30 \%$ resulting in different behaviors. This suggested that a $30 \%$ TS content corresponded to a solids threshold, above which methanogenesis was inhibited. Similarly, An et al. (2017) found that the ultimate biogas yield of sludge firstly improved and then decreased with TS increasing up to $10 \%$. The outcomes of both studies highlighted the limited mass transfer occurring under high TS conditions. This means that a proper balance among anaerobic digestion phases is needed to avoid the inhibition of the digestion process.

Aim of this study was to assess the effects of ozone dose, substrate particle size and total solid content on the anaerobic biodegradability of OFMWS samples. A Design of Experiment (DOE) strategy was adopted and the factors investigated were varied in a $2^{3}$ factorial design between "low" and "high" levels, selected according to previous studies.

\section{MATERIALS AND METHODS}

\subsection{Preparation of organic waste samples}

For experimental purposes, OFMSW samples were prepared in the laboratory, to ensure their reproducibility in the different test runs. The composition and the chemical-physical characteristics are given in Table 1.

The samples were then ground using a bench scale shredder model M20 (Universal IKA) and sieved to ensure that the particle size ranged between 1 and $3 \mathrm{~mm}$. Some samples were further processed to reduce the particle size below $1 \mathrm{~mm}$, to improve the homogeneity and reach the consistency typical of the press-extruded wet fraction (similar to a jam), as previously described (Novarino and Zanetti, 2012). The TS content of each sample was adjusted to either $10 \%$ or $15 \%$ by adding distilled water. These values were selected in order to keep operating conditions
TABLE 1: Composition by weight and main chemical-physical characteristics of the OFMSW samples.

\begin{tabular}{l|c}
\hline Composition by weight & \\
\hline Fraction & {$[\%$ w/w] } \\
\hline Fruit and vegetable & 78.6 \\
\hline Pasta and rice & 4.9 \\
\hline Bakery products & 6.4 \\
\hline Meat and fish & 8.2 \\
\hline Dairy products & 1.9 \\
\hline Chemical-physical characteristics & \\
\hline Parameter & Value \\
\hline TS [\%] & $23.52 \pm 0.27$ \\
\hline VS [\%TS] & $93.13 \pm 0.12$ \\
\hline SCOD [mg/L] & $16250 \pm 1573$ \\
\hline
\end{tabular}

closer to those of wet digestion, as previously (Cesaro and Belgiorno, 2013).

\subsection{Ozone pretreatment}

The ozonation of OFMSW samples was undertaken with a UV generator (model Ozone - Procom srl), using air supplied from a compressor. The ozone was introduced at the bottom of a glass reactor containing waste samples at a $0.16 \mathrm{~g}_{03} / \mathrm{g}_{\mathrm{TS}}$ ozone dose, selected on the basis of our previous work (Cesaro and Belgiorno, 2013).

Exhaust gas was extracted at the top of the reactor and passed through a Drechsel trap, filled with $200 \mathrm{~mL}$ of $2 \% \mathrm{KI}$ solution, in order to neutralize residual ozone. The methodology met with the Semi-Batch Standard Method 2350 US-EPA to determine the ozone demand.

\subsection{Analytical set up}

The main chemical-physical characteristics of the OFMSW samples were determined. Soluble Chemical Oxygen Demand (SCOD), total solid (TS) and volatile solid (VS) were evaluated according to Standard Methods (AWWAAPHA-WEF, 1998). The Standard procedure to determine the soluble COD (SCOD) was applied on each sample after centrifugation and filtration $(<0.45 \mathrm{~mm})$.

The experimental activity was carried out following the DOE strategy. To this end, ozone dose, waste particle size and total solid content were varied in a $2^{3}$ factorial design between a "low" (-) and a "high" (+) level, to evaluate eight pretreatment combinations (Table 2).

The response of the pretreated OFMSW samples was evaluated by their anaerobic biodegradability. This was assessed by batch tests, carried out under mesophilic conditions, using $500 \mathrm{~mL}$ flasks with $400 \mathrm{~mL}$ working volume. Digested sludge was used as inoculum and added to the substrate in a ratio of $0.5 \mathrm{~g}_{\mathrm{vs}}$ substrate $/ \mathrm{g}_{\mathrm{vs}}$ inoculum. The seed sludge (TS: $3.01 \pm 0.35$; VS: $57.81 \pm 4.84 \%$ TS) was collected from the anaerobic digester of a conventional wastewater treatment plant in Salerno (Italy) and incubated at $35^{\circ} \mathrm{C}$ for 5 days before use in order to reduce intrinsic gas production. No trace nutrients were added, nor $\mathrm{pH}$ of each batch was adjusted. After feeding, headspaces of the bottles were flushed with nitrogen gas and then 
TABLE 2: Combination plan for experimental tests.

\begin{tabular}{|c|c|c|c|}
\hline $\begin{array}{c}\text { Experimental } \\
\text { run }\end{array}$ & $\begin{array}{l}\text { Ozone dose } \\
{\left[\mathrm{gO}_{3} / \mathrm{gTS}\right]}\end{array}$ & $\begin{array}{c}\text { Total solid } \\
\text { [\%] }\end{array}$ & $\begin{array}{c}\text { Particle size } \\
\text { [mm] }\end{array}$ \\
\hline 1 & 0.16 & 15 & $1-3$ \\
\hline 2 & 0.16 & 10 & $1-3$ \\
\hline 3 & 0.16 & 15 & $<1$ \\
\hline 4 & 0.16 & 10 & $<1$ \\
\hline 5 & 0 & 15 & $1-3$ \\
\hline 6 & 0 & 10 & $1-3$ \\
\hline 7 & 0 & 15 & $<1$ \\
\hline 8 & 0 & 10 & $<1$ \\
\hline
\end{tabular}

sealed with rubber septa. Daily methane production was determined by a water displacement method (Esposito et al., 2012), and the cumulative production over 21 days was assessed. Results were expressed as the total volume of methane produced during the digestion period and calculated in the normal state $(273 \mathrm{~K}$ and $1013 \mathrm{hPa})$, per mass of added substrate, expressed in terms of VS (i.e. $\mathrm{L}_{\mathrm{CH} 4} / \mathrm{kg}_{\mathrm{VS}}$ ).

All the analytical determinations were performed in triplicate and average values have been used in the subsequent evaluation.

\subsection{Evaluation of the net energy gain}

The competitiveness of ozonation as pretreatment for anaerobic digestion should take into account the process efficiency as well as the energetic viability. In this study the latter was referred to the potential net energy gain $\left(E_{n e t}\right)$, which is the difference between the extra energy produced $\left(\mathrm{E}_{\text {produced }}\right)$ and the energy demand $\left(\mathrm{E}_{\text {pretreatment }}\right)$ for the pretreatment application (equation 1):

$E_{\text {net }}=E_{\text {produced }}-E_{\text {pretreatment }}$

The extra energy produced from the anaerobic digestion of ozonated substrates was calculated using equation 2 :

$E_{\text {produced }}=V_{\mathrm{CH} 4} * E_{\mathrm{CH} 4} * \eta$

where:

$\mathrm{V}_{\mathrm{CH} 4}$ is the surplus methane volume from ozonated substrates;

$\mathrm{E}_{\mathrm{CH} 4}$ is the methane energetic potential, assumed at 9.97 $\mathrm{kWh} / \mathrm{m}^{3}$;

$\eta$ is a conversion factor ( 0.38 for electrical energy; 0.45 for thermal energy).

The energy demand for ozone pretreatment is closely related to the detailed operation of device. For devices using air, this can vary across the range $2.5-40 \mathrm{kWh} / \mathrm{kgO}_{3^{\prime}}$ depending on the generation efficiency (Ariunbaatar et al., 2014b). In this study a high-energy efficiency ozone generator was used, and the lower value of $2.5 \mathrm{kWh} / \mathrm{kgO}_{3}$ was selected to calculate energy consumption.

\section{RESULTS AND DISCUSSION}

The preparation of the substrate for its use in anaerobic digestion is a fundamental step to optimize methane production. The hydrolysis of complex macro-molecules into soluble compounds depends on the nature of the substrate (Srisowmeya et al., 2020) and it has been largely claimed as the process rate limiting step in the anaerobic digestion of OFMSW (Kondusamy and Kalamdhad, 2014; Kumar Pramanik et al., 2019; Ren et al., 2018; Ye et al., 2018). Therefore, any strategy able to optimize this step results in either enhanced methane production or the speed up of the anaerobic bioconversion process.

Figure 1 shows the cumulative biomethane volumes produced after 21 days during the anaerobic digestion of OFMSW samples pretreated under different conditions.

Experimental results show that ozonation resulted in an increase in methane production ranging between 13 and $95 \%$, which is in good agreement with the findings of previous studies (Cesaro and Belgiorno, 2013; Ariunbaatar et al., 2014). The OFMSW samples were primarily fruit and vegetable peels, which are quite hard to degrade, due to their lignocellulosic components (Pagliaccia et al., 2019).The effects of ozone on this type of waste components was to promote more extensive degradation of the more resistant components, as confirmed by the increase in the ultimate production of methane after 21 days.

Among ozonated substrates, the best performance in terms of methane generation was found for the samples characterized by the lower TS content, despite the waste particle size.

A similar trend was also observed for the experimental studies on un-ozonated samples. The effect of total solid content on the performance of anaerobic digestion has been studied for a wide variety of substrates. As previously highlighted, several authors (Abbassi-Guenduz et al., 2012; An et al., 2017) investigated the role of TS content on solid waste anaerobic digestion: they found a slight decrease in methane production for TS increase up to a substrate-dependant threshold limit value, and attributed this outcome to mass transfer limitation. However, the increase with TS content needs to further account for microbial community change in the digester. Yi et al. (2014) compared the microbial community structure of mesophilic anaerobic digesters treating food waste with TS contents ranging from $5 \%$ to $20 \%$. They observed that the different performances in the digesters, in terms of VS reduction, reflected the relative abundance of the main microbial phyla. The same authors pointed out that the bioconversion of organic matter into the precursors for methane generators was the result of the role that each microbial population played in either the hydrolytic step or the acidogenic one. The experimental outcomes reported here are in good agreement with previous reports: other conditions being equal, a lower TS content did not hinder the biological conversion of the substrate, resulting in a higher ultimate methane production potential after 21 days. Depending on the operating conditions in terms of ozone supply and particle size range, the increase in the specific methane production after 21 days was found to be in the range $10-40 \%$.

The particle size influenced methane production as under the same ozonation and TS conditions, samples with the coarser particles $(1-3 \mathrm{~mm})$ provided the lower methane production. Izumi et al. (2010) had already pointed out that, when reducing the average food waste particle size from 


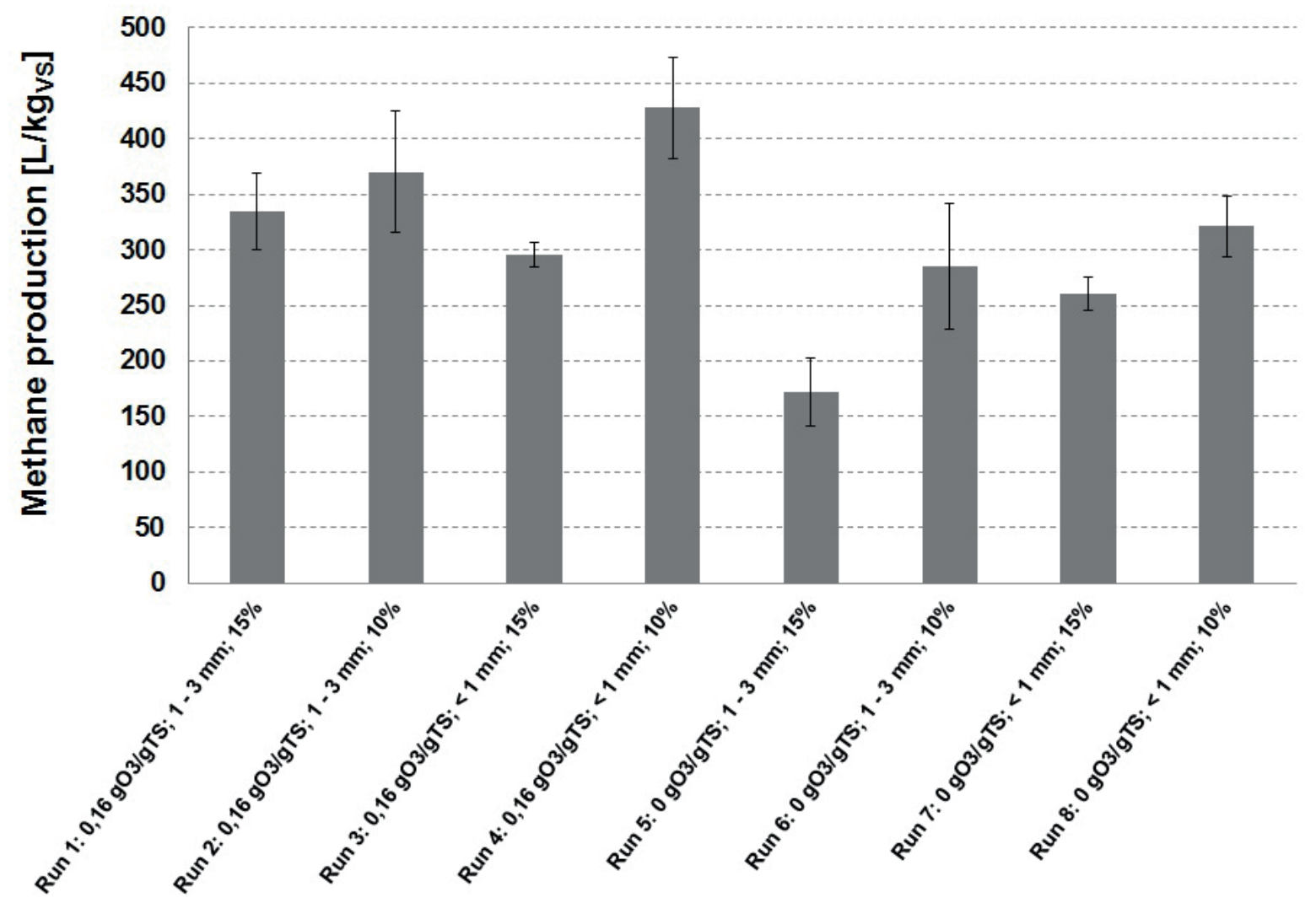

FIGURE 1: Cumulative methane production in 21 days for the investigated operating conditions.

0.888 to $0.715 \mathrm{~mm}$, a $28 \%$ methane increase occurred. Nevertheless, a further reduction of waste particle size can determine the acidification of the digestion medium due to the accumulation of volatile fatty acids and a subsequent inhibition of the process that, in turn, can lead to lower methane generation. The authors proved that, although waste size reduction results in the increase of the specific surface area for microbial attack, an excessive comminution can produce the formation of reaction intermediates that are not properly converted into methane and can create inhibitory conditions for the methanogenic bacteria in the digester.

The results of the present study are consistent with previous findings, with an $11-34 \%$ increase in methane generation from the press-extruded samples. However, the inverse relationship between waste particle size and volume of methane generated was not fully valid for the ozonated samples with the higher TS content. The comparison of test run $1\left(0.16 \mathrm{gO}_{3} / \mathrm{gTS} ; \mathrm{d}=1-3 \mathrm{~mm} ; \mathrm{TS}=15 \%\right)$ and test run $3\left(0.16 \mathrm{gO}_{3} / \mathrm{gTS} ; \mathrm{d}<1 \mathrm{~mm} ; \mathrm{TS}=15 \%\right)$ highlights that the methane generation from waste samples with the coarser particles was $12 \%$ higher than that from press-extruded samples. This is likely to be related to the combined effects of ozonation and press-extrusion on the more concentrated samples, which could result in a significant qualitative change in the substrate making it more suitable for microbial degradation kinetics.

The analysis of variance at a $95 \%$ confidence level was also performed on the anaerobic biodegradability trials. The F-test was used to estimate the statistically significant factors ( $p$-value < 0.05), which were found to be both the ozone dose and the total solid content. The combination of the three factors investigated was found to be significant as well, as shown in Table 3.

The particle size could not be considered a statistically significant factor: as the $p$-value was higher than 0.05 , the analysis of variance suggests that the variation of the experimental response associated to the corresponding variation of this factor (particle size) can be attributed to conditions other than the variation of the factor itself.

It is worth pointing out that such an outcome could reflect the choice of the values selected for this study. The assumption that smaller particle dimensions leads to an overall improvement of anaerobic digestion yield is not necessarily correct. Zhang and Banks (2013) studied the impact of different particle size distributions on anaerobic digestion of OFMSW and found that any increase of the specific methane generation occurred when the waste particle size was reduced from 4 to $2 \mathrm{~mm}$. Nevertheless, the same authors observed the increase in methane generation rate during the first 15 days of process. However, this evidence was considered not relevant, since the retention time of the substrate within anaerobic reactors often exceeds 15 days.

Experimental results highlight that ozonation is a viable pretreatment option to improve the generation of methane from OFMSW. However, as ozonation has high-energy consumption, its operation as OFMSW treatment prior to anaerobic digestion is only competitive if the energy produced from the surplus biogas can either balance or ex- 
TABLE 3: Results of the analysis of variance (ANOVA) and p-values.

\begin{tabular}{|c|c|c|c|c|}
\hline & Sum sq & Mean sq & F value & $\operatorname{Pr}(>\mathrm{F})$ \\
\hline A & 62831.69 & 62831.69 & 52.10381 & $9.081 \mathrm{E}-05$ \\
\hline B & 77834.03 & 77834.03 & 64.54465 & 4.236 E-05 \\
\hline $\mathrm{C}$ & 6263.535 & 6263.535 & 5.1941 & 0.052148 \\
\hline$A: B$ & 274.1508 & 274.1508 & 0.227342 & 0.646254 \\
\hline $\mathrm{B}: \mathrm{C}$ & 389.9638 & 389.9638 & 0.323381 & 0.585188 \\
\hline$A: C$ & 2881.274 & 2881.274 & 2.389325 & 0.160750 \\
\hline$A: B: C$ & 22833.48 & 22833.48 & 18.93489 & 0.002441 \\
\hline
\end{tabular}

where: $A$ is the ozone dose; $B$ is the TS content; $C$ is the particle size

ceed the energy consumption to run the ozonation device.

In this view, the potential net energy gain was estimated for all the operating conditions considered in this study and the results are summarized in Table 4.

If considering the potential net production of electric energy, it was possible to achieve an increase of $26 \mathrm{kWh} /$ $t_{\text {OFMSW }}$. This only occurred for the samples characterized by the coarser particles (1-3 mm) and the higher TS content (15\%), as the application of ozone on this kind of substrate almost doubled the production of methane. For the thermal energy, the potential net gain was found to be in the range 5 - $43 \mathrm{kWh} / \mathrm{t}_{\mathrm{OFMSW}}$. In this case, the best performance was obtained for the same kind of samples providing the only net electric energy gain.

It is worth pointing out that the evaluation of net energy was based on experimental results obtained at lab scale as well as in batch conditions: these are likely to change when applying ozone pretreatment on larger scale, in a continuously fed reactor. Morever, this study did not evaluate further aspects contributing to the production of methane from anaerobic digestion, related to the operating conditions of the biological process itself, such as the organic loading rate and the hydraulic retention time.

The economic viability for OFMSW pretreatment does not only depend on the energy balance, despite its key role. The higher degree of conversion of the organic matter into methane would also reduce the amount of digestate to be handled at the end of the anaerobic process, providing additional savings. Moreover, the oxidative potential of ozone could further promote the improvement of digestate quality, with particular reference to the presence of persistent organic pollutants, like polycyclic aromatic hydrocarbons (PAHs), polychlorinated biphenyls (PCBs) and pesticides.
These compounds may enter the anaerobic digester together with the OFMSW and concentrate in the digestate due to their poor biodegradability. The application of ozonation in improving the quality and degradability of benzo[a]pyrene-contaminated digestate was investigated by Cesaro et al. (2019). The key finding was the dependence of the integrated ozone/anaerobic digestion process on the biological stabilization extent of the digestate.

All these aspects have to be considered to evaluate the techno-economic competitiveness of ozonation for the valorization of OFMSW destined to anaerobic digestion, to properly promote its scale up.

\section{CONCLUSIONS}

This study evaluated the potential of ozonation as pretreatment of the organic fraction of municipal solid waste (OFMSW) for anaerobic digestion and influence of particle size and total solid (TS) content.

Experimental results pointed out that an ozone dose of $0.16 \mathrm{~g}_{\mathrm{O} 3} / \mathrm{g}_{\mathrm{TS}}$ can improve the specific methane generation in the range $13-95 \%$. Although the greatest specific methane volumes were obtained for samples characterized by a $10 \%$ TS content, the highest increase was obtained for the samples with $15 \%$ TS: in this case, the methane production was $95 \%$ higher than the one obtained for the untreated samples with the same characteristics in terms of TS content and particle size distribution. Such increase was also found to result in a positive net energy gain, with respect to either electrical or thermal energy. These outcomes suggest that ozonation can be an attractive OFMSW pretreatment, suitable to pursue the increase in TS content in anaerobic reactors. Conversely, the substrate size distribution was not found to be a statistically significant factor.

Experimental results are promising, but the overall competitiveness of a combined mechanical/ozonation treatment prior to OFMSW anaerobic digestion should take into account the economic affordability of this technology. Further tests at larger scale are thus necessary to optimize the operating conditions of the integrated ozonation/ anaerobic digestion process for OFMSW treatment. These tests should also provide the required data to carry out an economic feasibility assessment for its reliable scale up.

\section{AKNOWLED GEMENTS}

The authors wish to thank Paolo Napodano for his valuable support in the experimental work. Alessandra Cesaro

TABLE 4: Results of the potential net energy gain assessment for the investigated pretreatment conditions.

\begin{tabular}{|c|c|c|c|c|}
\hline Particle size (d) and TS content & $\begin{array}{c}\mathrm{d}=1-3 \mathrm{~mm} ; \\
\mathrm{TS}=15 \%\end{array}$ & $\begin{array}{c}\mathrm{d}=1-3 \mathrm{~mm} ; \\
\mathrm{TS}=10 \%\end{array}$ & $\begin{array}{l}\mathrm{d}<1 \mathrm{~mm} ; \\
\mathrm{TS}=15 \%\end{array}$ & $\begin{array}{l}\mathrm{d}<1 \mathrm{~mm} ; \\
\mathrm{TS}=10 \%\end{array}$ \\
\hline Methane surplus from ozonation at $0.16 \mathrm{gO}_{3} / \mathrm{gTS}\left[\mathrm{m}^{3} / \mathrm{tOFMSW}\right]$ & 23.0 & 8.1 & 4.9 & 10.1 \\
\hline Electric energy surplus [kWh/tOFMSW] & 86 & 30 & 18 & 38 \\
\hline Thermal energy surplus [kWh/tOFMSW] & 103 & 36 & 22 & 45 \\
\hline Energy consumption for ozonation [kWh/tOFMSW] & 60 & 40 & 60 & 40 \\
\hline Potential electric energy gain [kWh/tOFMSW] & 26 & -10 & -42 & -2 \\
\hline Potential thermal energy gain [kWh/tOFMSW] & 43 & -4 & -38 & 5 \\
\hline
\end{tabular}


would like to thank the Italian Ministry of Education, University and Research (MIUR) who provided financial support for her position as Assistant Professor at the University of Napoli Federico II in the frame of the research project entitled "Dipartimenti di Eccellenza” per Ingegneria Civile Edile e Ambientale - CUPE65D18000820006.

\section{REFERENCES}

Abbassi-Guendouz, A., Brockmann, d., Trably, E., Dumas, C., Delgenès, J.P., Steyer, J.P., Escudié, R., 2012. Total solids content drives high solid anaerobic digestion via mass transfer limitation. Bioresour. Technol. 111, 55-61.

An, D., Wang, T., Zhou, Q., Wang, C., Yang, Q., Xu, B., Zhang, Q., 2017. Effects of total solids content on performance od sludge mesophilic anaerobic digestion and dewaterability of digested sludge. Waste Manage. 62, 188-193.

Ariunbaatar, J., Panico, A., Esposito, G., Pirozzi, F., Lens, P.N.L., 2014 a. Pretreatment methods to enhance anaerobic digestion of organic solid waste. Appl. Ener. 123, 143-156.

Ariunbaatar, J., Panico, A., Frunzo L., Esposito, G., Lens, P.N.L., Pirozzi, F., 2014b. Enhanced anaerobic digestion of food waste by thermal and ozonation pretreatment. J. Environ. Manage. 146, 142-149.

AWWA-APHA-WEF, 1998. Standard Methods for the Examination of Water and Wastewater, 20th ed., American Public Health Association/American Water Works Association/Water Environment Federation, Washington, DC, USA.

Cesaro, A., Belgiorno, V., 2013. Sonolysis and ozonation as pretreatment for anaerobic digestion of solid organic waste. Ultrason. Sonochem. 20, 931-936.

Cesaro, A., Belgiorno, V., 2014. Pretreatment methods to improve anaerobic biodegradability of organic municipal solid waste fractions. Chem. Eng. J. 240, 24-37.

Cesaro, A., Belgiorno, V., Siciliano, A., Guida, M., 2019. The sustainable recovery of the organic fraction of municipal solid waste by integrated ozonation and anaerobic digestion. Res. Conserv. Recycl. 141, 390-397.

Dahiya, S., Kumar, A.N., Shanthi Sravan, J., Chatterjee, S., Sarkar, O., and Mohan, S.V., 2018. Food waste biorefinery: Sustainable strategy for circular bioeconomy. Bioresour. Technol. 248, 2-12.

De Vrieze, J., Arends, J.B.A., Verbeeck, K., Gildemyn, S., Rabaey, K., 2018. Interfacing anaerobic digestion with (bio)electrochemical systems: Potentials and challenges. Water Res. 146, 244-255.
Esposito, G., Frunzo, L., Liotta, F., Panico, A., Pirozzi, F., 2012. Bio-methane potential tests to measure the biogas production from the digestion and co-digestion of complex organic substrates. Open Environm. Eng. J. 5, 1-8.

Hjorth, M., Gränitz, K., Adamsen, A.P., Møller, H.B., 2011. Extrusion as a pretreatment to increase biogas production. Bioreour. Technol. 102 (8), 4989-4994.

Izumi, K., Okishio, Y., Nagao, N., Niwa, C., Yamamoto, S., Toda, T., 2010. Effects of particle size on anaerobic digestion of food waste. Int. Biodeterior. Biodegrad. 64, 601-608.

Kondusamy, D., Kalamdhad, A.S., 2014. Pre-treatment and anaerobic digestion of food waste for high rate methane production - a review. J. Environm. Chem Eng. 2, 1821-1830.

Kumar Pramanik, S., Binti Suja, F., Zain, S.M., Kumar Pramanik, B., 2019. The anaerobic digestion process of biogas production from food waste: prospects and constraints. Bioresour. Technol. Rep. 8, 100310.

Li, Y., Chen, Y., Wu, J., 2019. Enhancement of methane production in anaerobic digestion process: a review. Appl. Ener. 240, 120-137.

Novarino, D., Zanetti, M.C., 2012. Anaerobic digestion of press-extruded OFMSW. Bioresour. Technol. 104, 44-50.

Pagliaccia, P., Gallipoli, A., Gianico, A., Gironi, F., Montecchio, D., Pastore, C., di Bitonto, L., Braguglia, C.M., 2019. Variability of food waste chemical composition: impact of thermal pre-treatment on lignocellulosic matrix and anaerobic biodegradability. J. Environm. Manage. 236, 100-107.

Ren, Y., Yu, M., Wu, C., Wang, Q., Gao, M., Huang, Q., Liu, Y., 2018. A comprehensive review on food waste anaerobic digestion: research updates and tendencies. Bioresour. Technol., 247, 1069-1076.

Srisowmeya, G., Chakravarthy, M., Nandhini Devi, G., 2020. Critical considerations in two-stage anaerobic digestion of food waste - a review. Renew. Sust.Energy Rev. 119, 109587.

Sievers, M., Ried, A., Koll, R., 2004. Sludge treatment by ozonation: evaluation of full-scale results. Water Sci. Technol. 49, 247-253.

Xu, F., Li, Y., Ge, X., Yang, L., Li, Y., 2018. Anaerobic digestion of food waste - Challenges and opportunities. Bioresour. Technol. 247, 1047-1058

Yi, J., Dong, B., Jin, J., Dai, X., 2014. Effects of increasing total solids contents on anaerobic digestion of food waste under mesophilic conditions: performance and microbial characteristics analysis. PLoS One 9(7), 1-10.

Ye, M., Liu, J., Ma, C., Li, Y.Y., Zou, L., Qian, G., Ping Xu, Z., 2018. Improving the stability and efficiency of anaerobic digestion of food waste using additives: a critical review. J. Clean. Prod. 192, 316326.

Zhang, Y., Banks, C.J., 2013. Impact of different particle size distributions on anaerobic digestion of the organic fraction of municipal solid waste. Waste Manage. 33, 297-307. 